\title{
Esau e Jacó ou o ser e o fazer
}

\author{
Dilson Ferreira da CRUZ (FFLCH- USP)
}

RESUMO: Em Esaú e Jacó, Machado de Assis faz uma notável reflexão sobre o ser e o fazer, a qual acaba por evidenciar a imperfeição que envolve todos, especialmente um dos atores centrais do romance: o Brasil.

PALAVRAS CHAVE: Semiótica, modalidades factivas, modalidades epistemológicas, Esaú e Jacó, Machado de Assis.

RESUMÉ: Dans Esaú e Jacó, Machado de Assis propose une notable réflexion sur l'être et le faire, laquelle fini pour mettre en évidence l'imperfection qui touche à tous, et d'une façon spécial l'un des acteurs les plus importants du roman : le Brèsil.

MOTS-CLÉS: Sémiotique, modalités factives, modalités épistémologiques, Esaú e Jacó, Machado de Assis 
No ensaio de abertura de Da Imperfeição, intitulado O Deslumbramento, Greimas analisa uma passagem de Sexta-feira ou os limbos do pacífico, de Michel Tournier, em que Robinson, personagem central, fica deslumbrado com o "silêncio insólito" de uma gota de água que "renuncia decididamente" a cair de uma clepsidra em uma bacia. Como tais gotas funcionavam como os ponteiros de um relógio, Robinson acredita que se operara mesmo uma inversão do curso do tempo e, desse modo, vê abrirse para ele a possibilidade de uma outra percepção da ilha em que vivia como náufrago. Ao longo da análise, Greimas mostra como nessa passagem Tournier constrói uma parábola da apreensão estética da realidade pelo homem, a qual teria como elementos constitutivos a relação estésica entre sujeito e objeto, a unicidade da experiência e a esperança de uma total conjunção por advir entre esses dois actantes (p.30).

Inspirados pela leitura de Greimas, desejaríamos, de maneira bastante despretensiosa, refletir sobre um processo também presente na passagem acima, mas não explicitado pelo semioticista: a permanente interação entre o fazer - ou seja, no caso do romance de Tournier, o percurso da gota que executa seu programa narrativo de cair sobre a bacia e assim servir de relógio - e o ser, isto é, a mesma gota que se recolhe em sua perfeição de ser em plena conjunção com os objetos que a constituem e que se define por sua essência e não pelo seu percurso narrativo, pelo seu fazer. Em outras palavras, na mesma passagem estaria em jogo a interação entre as modalidades veridictórias, relacionadas ao ser, e as modalidades factivas, relativas ao fazer, ambas naturalmente presentes no percurso narrativo de qualquer sujeito, mas de tal forma amalgamadas que seu casamento quase sempre passa despercebido. Observe-se que embora Greimas não desenvolva tal raciocínio, pois a questão que lhe interessa é de natureza estética, tal abordagem é possível se atentarmos para a análise que o autor faz desse trecho:

As "coisas", para alcançar a perfeição, efetuam antes de tudo dois tipos de movimentos diametralmente opostos: primeiro, elas se inclinam umas em direção às outras — conforme sua funcionalidade e sua deterioração —, em seguida, elas recaem em "sua essência" e eclodem — elas se erguem em sua essência e é somente então que se põem a existir sem justificativa, na perfeição de sua imobilidade (Greimas, 2002: 27).

É isso que se passou com a gota que Robinson observava: primeiro, ela se inclinara em direção à sua funcionalidade - cair na bacia - para depois se retrair, voltar-se para si própria. A "perfeição" da gota, assim proposta, nasceria, no caso do romance de Tournier, de uma imperfeição, de um fazer que não se realiza: o fato de as coisas inclinarem-se em direção umas às outras, conforme sua funcionalidade e sua usança, mas, no último instante, recusarem esse fazer, que permanece incompleto. Contudo, é a incompletude do fazer, sua imperfeição, que acaba por permitir que a interação das duas modalidades seja observada: primeiro o fazer que não se realiza, depois a reafirmação do ser, a junção do sujeito com os objetos, modais ou descritivos, que definem sua essência e que o permitem prescindir de um fazer para realizar-se. Ora, a imbricação das duas modalidades há muito já está nas bases da teoria semiótica. Recordemos. 
A semiótica considera que o agir ou a realização de qualquer ato, portanto, de qualquer transformação, é constituída pelo encadeamento de dois enunciados: um enunciado de fazer regendo um enunciado de ser. Em outras palavras, um sujeito $\mathrm{S}_{1}$ transmite competência para um sujeito $S_{2}$ para que este altere sua relação de junção com um objeto $\mathrm{O}_{2}$. É a transformação da relação de $\mathrm{S}_{2}$ com $\mathrm{O}_{2}$ que constitui o objeto $\mathrm{O}_{1}$ com o qual interage o sujeito $S_{1}$. Esquematizando, temos:

$\mathrm{F}\left[\mathrm{S}_{1} \rightarrow \mathrm{O}_{1}\left(\mathrm{~S}_{2} \cup\right.\right.$
$\left.\mathrm{O}_{2}\right]$

Naturalmente, é indiferente se $S_{1}$ e $S_{2}$ estão ou não sincretizados em um mesmo ator, o que é relevante é o fato de que o fazer sempre é constituído por um fazerser, ou seja, o fazer sempre consiste em produzir uma mudança na relação de junção de $\mathrm{S}_{2}$ (da disjunção para conjunção a ou vice versa) com um objeto de valor, o qual define sua identidade $\left(\right.$ de $\left.S_{2}\right)$. Assim, vê-se que qualquer ato encerra em si a tensão entre fazer e ser, ou, o que é óbvio, entre dois estados diferentes de ser, intermediados por um fazer. Observe-se que, no caso da gota, essa tensão se manifesta inclusive em termos eidéticos, pois à medida que seu fazer, isto é, cair sobre a bacia, evolui, sua forma também se altera: antes de iniciar seu percurso, ela era esférica, depois passa a ser piriforme e volta novamente à forma anterior. Leiamos essa passagem do romance:

Para dizer a verdade, o silêncio insólito que reinava no aposento fora-lhe revelado [a Robinson] pelo ruído da última gota que caia na bacia de cobre. Volvendo a cabeça, ele verificou que a gota seguinte aparecia timidamente no garrafão vazio, esticava-se, adotava um perfil piriforme, depois hesitava, como que desencorajada, retomava sua forma esférica, chegava a remontar à sua origem, renunciando decididamente a cair, e até esboçando uma inversão no curso do tempo.

Retomando a questão das modalidades, registre-se que o fazer, portanto, as modalidades factivas, relaciona-se à intencionalidade; isto é, a querer, saber, poder ou dever, o que permite ao seu sujeito apresentar-se como um ator ativo, que acumula em si todas as potencialidades necessárias à sua performance. Já as modalidades do ser, isto é, as modalidades veridictórias, relacionam-se aos jogos de ser e parecer, à afirmação ou à negação da imanência por sua manifestação; relacionam-se, portanto, mais com a manutenção de um mesmo estado de junção do sujeito com os objetos de valor do que com a alteração dessa relação, a qual equivale, como se viu, à transformação.

$$
* * * * *
$$

Naturalmente, o romance de Tournier não é a única ocasião de flagrar as duas modalidades em interação. O romance Esaú Jacó, de Machado de Assis, oferece uma outra oportunidade não menos rica. Recordemo-lo. Trata-se da história de dois irmãos gêmeos, Pedro e Paulo, que têm em comum apenas o fato de serem univitelinos, posto que se opõem em absolutamente todas as demais questões (na verdade, um é o contraditório do outro, o que por si só já daria outra análise). A única exceção é a paixão 
que ambos nutrem por Flora, cujo amor disputam incessantemente até que ela vem a morrer, possivelmente em razão da disputa no centro da qual se encontra. Nem a morte da amada, nem a da mãe (ocorrida pouco tempo depois da de Flora) são suficientes para fazer os dois irmãos se reconciliarem - e isso apesar da promessa feita à última quando ela estava à morte. O romance termina com os dois irmãos bem sucedidos socialmente, mas envolvidos em uma disputa sem fim, tal como previra uma vidente, a cabocla do Castelo, no início da trama.

Uma primeira leitura talvez pudesse levar à conclusão de que se trata de um velho triângulo amoroso associado ao tema do duplo, tema não raro na literatura. Entendemos, porém, que as coisas se passam de modo outro e que o romance propõe uma discussão mais interessante, relacionada à interação entre o ser e o fazer, a qual se desenvolve em dois planos: em um deles, há o conflito dos dois gêmeos que se opõem principalmente em função dos investimentos modais que recebem. Em outro, a mesma dicotomia de modalidades se coloca, porém focada em um único ator com o qual os dois irmãos também se relacionam e que também vive seu dilema entre o ser e o fazer: o Brasil. Desse modo, uma possível leitura do romance se articularia em um jogo entre as modalidades veridictórias e as factivas ou entre permanência e mudança. A título de exemplo, recordemos a passagem em que os dois irmãos trocam suas posições políticas. Pedro, que sempre fora monarquista, de repente torna-se republicano, enquanto Paulo, que defendera o regime de governo implantado por Deodoro desde o seu nascimento e mesmo antes, agora passa a atacá-lo. Mudavam as opiniões, mas não as desavenças. D Cláudia, amiga da família, acredita que tudo não passava de um acordo dos dois irmãos para jamais concordarem, mas Aires, o narrrador, propõe outra explicação:

D. Cláudia tinha que era cálculo de ambos para se não juntarem nunca; - opinião que Natividade [mãe dos gêmeos] aceitaria, finalmente, senão fora a de Aires.

(...)

- Mas que pode ser então?

(...). Ao fim de três minutos, [Aires] segredou a Natividade: $-\underline{\mathrm{A}}$ razão parece-me ser que o espírito de inquietação reside em Paulo, e o de conservação em Pedro. Um já se contenta do que está, outro acha que é pouco e pouquíssimo, e quisera ir ao ponto a que não foram homens. Em suma, não lhes importam formas de governo, contanto que a sociedade fique firme ou se atire para diante. (...).

(...) Em verdade, a mãe dos gêmeos não quis outra explicação. Nem por isso a discórdia morreria entre eles, que apenas trocavam de armas para continuar o mesmo duelo. Ouvindo esta conclusão, Aires fez um gesto afirmativo, e chamou a atenção de Natividade para a cor do céu, que era a mesma, antes e depois da chuva. Supondo que havia nisto algo simbólico, ela entrou a procurá-lo, e o mesmo farias tu, leitor, se lá estivesses; mas não havia nada.

(Obra Completa, p. 1.086-7 - grifos meus) 
Recordem-se agora os termos de Greimas ao comentar o romance de Tournier: as coisas, para adquirir sua perfeição, executam dois movimentos opostos: ora inclinam-se umas em direção às outras, ora recaem sobre sua essência. O mesmo movimento que era executado pela célebre gota agora está repartido entre os dois irmãos (gêmeos, não custa lembrar): Paulo é movido pelo fazer, pela inquietação, para usar os termos de Aires, pelo caminhar das coisas em direção umas às outras. Já em Pedro reside o espírito da conservação, pois sempre busca a manutenção de um mesmo estado de junção, portanto, o ser em detrimento do fazer. Aí está novamente o mesmo jogo: precipitar-se rumo ao seu destino (o fazer que move Paulo) ou manter tudo como está (o ser defendido por Pedro). Veja-se ainda que o trecho acima deixa claro que o pendor para o ser ou para o fazer não é apenas uma característica a distinguir os dois irmãos, mas é mesmo o princípio que opõe um ao outro. De acordo com Aires, a rivalidade existente entre eles se traduz na oposição entre a conservação e a mudança, ou, em termos modais, entre as modalidades epistemológicas (relativas ao ser) e as factivas (referentes ao fazer). São termos muito semelhantes aos usados por Greimas \& Courtés para descrever as duas modalidades: para os autores do Dicionário a oposição entre os enunciados de ser e de fazer remete, ainda que de forma apriorística e intuitiva, à dicotomia entre conservação e mudança (1993: 144), a mesma, portanto, que opõe os filhos de Natividade.

O fato de os dois gêmeos serem fisicamente idênticos, detentores das mesmas modalidades, e sujeitos de percursos também idênticos: casar-se com Flora e ascender socialmente, ou, como diria a cabocla do castelo, subir, subir, subir, não é gratuito, mas confirma que os dois irmãos constituem, na verdade, um único ator ${ }^{\mathrm{i}}$, que realiza o mesmo percurso, mas que em um momento privilegia o fazer, e, em outro, o ser, como, aliás, ocorre com qualquer sujeito e com a gota do texto de Tournier. A novidade do texto de Machado é o fato de podermos observar isoladamente cada uma das modalidades em funcionamento. Encerrando esses comentários, registre-se que observação de Aires sobre a cor do céu, que era a mesma, antes e depois da chuva, reafirma a isotopia com a qual estamos lidando e que é constituída da mesma dicotomia: de um lado, o fazer, a transformação, a mudança, o inclinar das coisas em direção umas das outras, a chuva que transformara o aspecto do céu; de outro, o ser e sua permanência, o fato de o céu voltar a ter o mesmo aspecto, voltar a ser idêntico a ele mesmo, tal como a gota que deixa de ser esférica, assume a forma de pêra e retorna à sua forma original.

No entanto, conforme citado, em um segundo plano, outro percurso é constituído ao longo do romance: o do próprio país em que vivem as personagens. De fato, a menção ostensiva a fatos da história brasileira, como não ocorre em nenhuma outra obra de Machado, à exceção das crônicas, ${ }^{\text {ii }}$ acaba fazendo com que o próprio país se constitua em sujeito. Aspectos da vida nacional, até então só abordados nas colunas que Machado mantinha nos jornais estão todos presentes em Esaú e Jacóiii: a crise de $1855^{\text {iv }}$, a Abolição da Escravaturav; o célebre baile da Ilha Fiscal, derradeiro do Império, descrito em primeira pessoa por Aires nos capítulos XLVIII e XLIX; a Proclamação da República, que ocupa nove capítulos praticamente inteiros ${ }^{\mathrm{vi}}$; vários fatos que se seguiram a ela, como a Constituição de $24.02 .1891^{\text {vii; }}$ a política do 
Encilhamento ${ }^{\text {viii, }}$, do qual Santos teria sido um dos protagonistas; o golpe de Estado de Deodoro e o contragolpe de Floriano, que derruba de novo a carreira de Batista ${ }^{\mathrm{ix}}$; a Revolta da Armada e a Revolução Federalista ; além do fato de o próprio marechal Floriano, surgir como personagem e título do capítulo LXVII, Visita ao Marechal. Note-se que estas não são simples referências, mas constituem mesmo o arcabouço do livro, pois a oposição dos dois irmãos se pauta em boa medida pela forma como sancionam o fazer do sujeito Brasil, com natural destaque para oposição entre a Monarquia e República. Além disso, em todos esses episódios, discutidos intensamente ao longo do romance, fica claro que esses eventos implicariam, ao menos em tese, uma profunda transformação do país. ${ }^{\text {xi }}$ Todavia, o conselheiro deixa claro em inúmeras ocasiões que duvida dessas mudanças, que estas se assemelhariam ao movimento da nossa gota lá na clepsidra de Robinson: tudo indica que haveria uma mudança, tal como a gota que assumia ares de pêra e parecia precipitar-se rumo à bacia, mas, no último instante, reassume sua forma esférica, característica de sua identidade, e volta para dentro do garrafão. É a mesma tensão, porém colocada em outros termos. Vejamos, brevemente, duas dessas passagens - e há muitas outras.

Primeiro, o divertido episódio envolvendo o vizinho de Aires, Custodio, que, diante da Proclamação da República, fica sem saber qual nome colocar em seu comércio, até então chamado Confeitaria do Império (capítulos XLIX, LXII e LXIII). Custódio havia mandado fazer uma nova tabuleta para seu estabelecimento, a qual, em decorrência da Proclamação da República, passa a ser hostilizada por populares ainda na oficina do homem que a fabricara. O confeiteiro, então, corre à casa do Conselheiro à procura de uma solução para o problema; de um novo nome para seu negócio, pois teme que a manutenção do nome Confeitaria do Império lhe cause graves problemas junto à clientela. Aires faz algumas sugestões:

— Mas pode pôr "Confeitaria da República"...

- Lembrou-me isso, em caminho, mas também me lembrou que, se daqui a um ou dois meses, houver nova reviravolta, fico no ponto em que estou hoje, e perco outra vez o dinheiro.

(...) Aires propôs-lhe um meio-termo, um título que iria com ambas as hipóteses, — "Confeitaria do Governo."

- Tanto serve para um regímen como para outro.

- Não digo que não, e, a não ser a despesa perdida... Há, porém, uma razão contra. V. Ex ${ }^{a}$. sabe que nenhum governo deixa de ter oposição. As oposições, quando descerem à rua, podem implicar comigo, imaginar que as desafio, e quebrarem-me a tabuleta; entretanto, o que eu procuro é o respeito de todos.

\section{(...)}

- Olhe, dou-lhe uma idéia que pode ser aproveitada, e, se não a achar boa, tenho outra à mão; e será a última. Mas eu creio que qualquer delas serve. Deixe a tabuleta pintada como está, e à direita, na ponta, por baixo do título, mande escrever estas palavras que explicam o título: "Fundada em 1860." Não foi em 1860 que abriu a casa?

(...) 
- A outra idéia não tem a vantagem de pôr a data à fundação da casa, tem só a de definir o título, que fica sendo o mesmo, de uma maneira alheia ao regímen. Deixe-lhe estar a palavra império e acrescente-lhe embaixo, ao centro, estas duas, que não precisam ser graúdas: das leis. Olhe, assim, concluiu Aires, sentando-se à secretária, e escrevendo em uma tira de papel o que dizia.

(Obra Completa, p. 1.029-30)

A mudança de regime, que, evidentemente, criava uma nova identidade para o sujeito Brasil, criara um problema para Custódio e o levara a querer mudar também o nome do estabelecimento. Ocorre que a nova mudança poderia não ser definitiva: a República poderia cair a qualquer momento, permitindo o retorno da Monarquia e ele teria de fazer nova alteração. As soluções propostas por Aires baseiam-se, em síntese, em um nome que englobe os dois estados distintos pelos quais passara o país e assim anule, no modo do parecer, qualquer mudança, passada ou futura. Aires sugere três alternativas: Confeitaria do governo, Confeitaria do império das leis e acrescentar a data de fundação do estabelecimento. O confeiteiro recusa-as todas por motivos variados, mas que têm em comum o temor de que os três nomes dêem a entender que a confeitaria estaria em disjunção com os valores que seriam os de sua clientela: uma adesão ao governo, na primeira hipótese; um tom antiquado, na segunda; e a manutenção de uma relação com o império, na terceira, caso a expressão "das leis" não fosse percebida pelo transeunte. Observe-se que Aires busca uma solução que faça parecer que não houve transformação, que o ser permaneceu inalterado. Já Custódio rejeita-as todas pela mesma razão: o temor de que ao anular o fazer ele deixe, no modo do parecer, de estar em conjunção com os valores da clientela. Como quer que seja, o problema de Custódio pode ser colocado nos seguintes termos: de um lado, receia acompanhar as transformações, pois não sabe se serão definitivas; de outro, não pode manter a placa do jeito que está, pois as mudanças, definitivas ou não, impedem a manutenção da conjunção com os valores da clientela.

Outra passagem que explicita o confronto das duas modalidades está em um diálogo que Aires mantém com Santos, pai dos gêmeos. Novamente, vem à tona o mesmo dilema: as mudanças seriam reais ou existiriam apenas no modo da aparência? $\mathrm{E}$ se forem reais, poderiam prejudicar os interesses de Santos? Aires procura tranqüilizálo:

Aires quis aquietar-lhe o coração. Nada se mudaria; o regímen, sim, era possível, mas também se muda de roupa sem trocar de pele. Comércio é preciso. Os bancos são indispensáveis. No sábado, ou quando muito na segunda-feira, tudo voltaria ao que era na véspera, menos a Constituição.

(Obra Completa p. 1.031 - grifos meus)

Para Aires, a mudança de regime de governo equivalia à de mudança de roupa: transformação no nível da manifestação, mas não da imanência. Mais uma vez, as coisas avançam em direção umas às outras para depois voltar ao que eram. Repare na ironia quando Aires afirma que tudo voltaria ao que era na véspera, menos a Constituição. É curioso que tudo pudesse continuar a ser o que era, com exceção, justamente, da Constituição, que é conjunto de leis que rege o Estado e, 
consequentemente, a sociedade. Naturalmente, trata-se de uma impossibilidade, pois equivale a um fazer que é desprovido de transformação do ser. A única possibilidade para a assertiva ser verdadeira é a Constituição não ter influência no dia a dia dos cidadãos, o que significa que ela seria uma Constituição apenas no modo do parecer, mas não do ser; uma falsa constituição, portanto. Como se sabe, os anos nos quais se passam os fatos narrados por Aires foram, talvez, os mais tumultuados de toda a história do Brasil. A Abolição da Escravatura e a Proclamação da República, por exemplo, poderiam desencadear mudanças estruturais em todo o país. Todavia, na visão de Aires, pode-se mudar de roupa sem mudar de pele; pode-se mudar a aparência sem alterar a essência. Assim, a questão que opunha os dois irmãos, o fazer e o ser, é também a mesma que se coloca para o País e para Custódio: como realizar um percurso em que o ser e o fazer não tenham um encadeamento lógico entre si.

A leitura de Esaú e Jacó convida ainda a outra reflexão: em que medida a discussão proposta por Machado continua válida? Será que o dilema entre a manutenção de um estado e sua transformação continua atual? Será que esse fazer sem uma transformação real do ser continua a ser discutido? Entendemos que propaganda política realizada pelos principais candidatos à Presidência da República nas eleições de 2006 oferece uma oportunidade para um início de conversa, necessariamente inconclusivo, dada a impossibilidade de aprofundá-la neste espaço.

Nos discursos dos principais candidatos sobressai uma diferença, que, afinal, acaba por confirmar a existência de um quadro de valores bastante homogêneo: de um lado, há o candidato do governo, que busca a reeleição, e que a propósito dos escândalos que abalaram sua imagem, e a do partido ao qual pertence, afirma que nem ele nem o partido mudaram, que continuam os mesmos, sempre em conjunção com os valores que definiram sua identidade: ética, justiça social, democracia, para ficarmos nos mais citados. Por outro lado, quando o assunto é a situação do país, o discurso passa a ser outro: o Brasil, ao contrário do seu presidente ou do partido no poder, teria mudado sim, e muito! Teria passado da disjunção com a justiça, a falta de saúde, a honestidade, a riqueza, para a conjunção (ou, vá lá, uma menor disjunção) com esses mesmos valores.

Atente-se agora para o discurso da oposição, tanto à esquerda quanto à direita: no que diz respeito ao presidente e seu partido, não se questionam os valores em jogo e, a rigor, nem mesmo sua conjunção com eles em tempos idos; o que se afirma é que tal sujeito mudou, passando da conjunção anterior para a disjunção nos dias atuais. $\mathrm{O}$ presidente e o seu partido, segundo a propaganda oposicionista, teriam se transformado, preferindo a corrupção em detrimento da ética, trocando a democracia por tendências autoritárias e substituindo uma verdadeira justiça social pelo mesmo assistencialismo retrógrado que antes combatiam. A mesma inversão se opera quando o assunto é o país: o Brasil não teria mudado, ou não para melhor: a política econômica seria a mesma do governo anterior, seu PIB estaria praticamente estagnado e no campo social a evolução seria, na verdade, o continuísmo do processo iniciado anteriormente. Enfim, a divergência entre situação e oposição, no que se refere ao presidente e seu partido, não se dá em relação à conjunção anterior de ambos com determinados valores, mas em relação à permanência de tal estado. Quando o assunto é o país, a divergência não tem 
por foco o estado atual, mas, principalmente, a existência de uma transformação em relação a um estado anterior.

Evidentemente, nesse espaço não cabem juízos de valor a respeito do discurso de um ou de outro candidato. No entanto, deve-se observar que a dicotomia entre ser e fazer, entre permanência e transformação, continua a se fazer presente nos discursos atuais, sem ter sido resolvida - e a atualidade Machado de Assis, depois de tantas mudanças constitucionais, parece apontar para a mesma conclusão. Sob visões que se apresentam como opostas, parece que a mesmice surge como única possibilidade: somos os mesmos bradam uns; o país é o mesmo retrucam outros. Os discursos da situação e da oposição, assim como o dilema de Custódio, parecem propor a existência da mesma tensão vivida pela gota: precipitar-se rumo ao fazer ou manter-se no ser; um movimento que se sempre se inicia, mas jamais se consuma. Contudo, diferentemente da célebre gota, esse jogo de estagnação e movimento não produz uma experiência estética inédita; não leva seus expectadores - ao contrário do que ocorreu com Robinson, que, por meio do evento da clepsidra, percebeu a existência de uma outra ilha onde a estética se sobrepunha à funcionalidade - a um deslumbramento, mas, antes, como afirma Greimas no último ensaio de Da Imperfeição, à evidência de valores que vivem seu crepúsculo (2002: 83), de uma falta generalizada de símbolos, os quais foram substituídos por uma ideologia da ação pela ação, isto é, um fazer que não rege nem é regido pelo ser.

Como alternativa, Greimas propõe uma nova relação entre funcionalidade e estética, mediante a ressemantização dos objetos gastos que nos rodeiam e das relações intersubjetivas esgotadas ou prestes a ser: no primeiro caso, vê-se a estética introduzindo-se na funcionalidade do cotidiano; no segundo, um desejo de conduzir o cotidiano em direção a um alhures (2002: 85). Tanto em um caso quanto em outro estaria em jogo uma percepção e uma apreensão estéticas do fazer e do ser, único meio pelo qual se poderia alcançar o novo. É o que propõe Greimas nos últimos parágrafos de Da imperfeição (2002: 91):

Vãs tentativas de submeter o cotidiano ou dele esvair-se: busca do inesperado que foge. E, todavia, os valores ditos estéticos são os únicos que, rejeitando toda negatividade, nos arremessam para o alto. A imperfeição aparece como um trampolim que nos projeta da insignificância em direção ao sentido.

$O$ que resta? A inocência: sonho de um retorno às nascentes quando o homem e o mundo constituíam um só numa pancália original. Ou a vigilante espera de uma estesia única de um deslumbramento ante o qual não nos encontraríamos obrigados a fechar as pálpebras .

\section{REFERÊNCIAS BIBLIOGRÁFICAS}

ASSIS, Joaquim Maria Machado de. Obra completa. Rio de Janeiro: Nova Aguilar, 1997, 3 vol.

GreIMAS, Algirdas Julian. Da imperfeição. Trad. Ana Cláudia de Oliveira. São Paulo: Hacker, 2002. 
Du sens II. Paris: Seuil, 1983.

Maupassant. La sémiotique du texte: exercices pratiques. Paris: Éditions du Seuil, 1976

e Courtés Joseph. Sémiotique, dictionnaire raisonné de la théorie du langage I. Paris: Hachette, 1979.

TOURNIER, Michel. Vendredi ou les limbes du Pacifique. Paris : Galimard / Folio, 1972.

\section{Como citar este artigo:}

CRUZ, Dilson Ferreira da. Esau e Jacó ou o ser e o fazer. Estudos Semióticos, Número 3, São Paulo, 2007. Disponível em <www.fflch.usp.br/dl/semiotica/es>. Acesso em "dia/mês/ano".

\footnotetext{
${ }^{\mathrm{i}}$ Ao considerar que Pedro e Paulo constituem um único ator seguimos o procedimento de Greimas em Maupassant - la semiotique du texte exercices pratiques, em que o autor considera os dois amigos do conto de Maupassant, Morissot e M. Sauvage, um único ator. Eis a explicação do semioticista:

Consideramos atores individuais não apenas atores providos de uma figura

individual, mas também pares de diferentes naturezas (gêmeos, avó e netinho,

etc.) bem conhecidos na mitologia (Greimas, 1976: 22)

ii A situação política do Brasil sempre freqüentou as crônicas de Machado, mas passa a ganhar um espaço maior a partir da coluna Bons Dias (1888-1889) e cresce em $A$ Semana (1892-1897), ambas publicadas no Jornal Gazeta de Notícias. Por outro lado, está quase completamente ausente dos romances, à exceção, justamente, de Esaú $e$ Jacó:

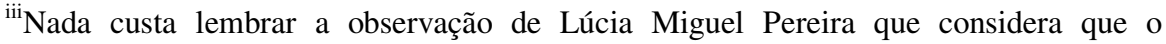
verdadeiro "autor" das crônicas de A Semana é Aires e não Machado de Assis:

Esse conselho dado logo no início das colaborações semanais na Gazeta de Notícias, cheira a Aires. Desse momento em diante não é mais possível separar os dois sósias. Machado adota o criado, o gosto, a polidez e a indiferença de Aires. Esse vai se deixando dominar por ele. (1988: 245).

${ }^{\text {iv }}$ Obra Completa, vol. I, p. 954

${ }^{v}$ Idem, p.992

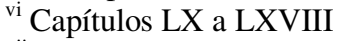

vii Idem, p. 1.056

viii Ver capítulo LXXIII, cujo título é Um Eldorado e LXXXVII
} 


\begin{abstract}
${ }^{\text {ix }}$ Ver capítulo LXXII
${ }^{x}$ Idem, p. 1.085

xi Com tal comentário não se pretende analisar o romance, mas, tão somente, mostrar que seus principais atores - Pedro Paulo e o Brasil - caracterizam-se, também, pelo pendor maior ou menor para as modalidades citadas
\end{abstract}

